CENDEKIA, Vol. 9, No. 1, April 2015

p ISSN: 1978 2098; e ISSN: 2407 8557; Web: cendekia.pusatbahasa.or.id

Pusat Kajian Bahasa dan Budaya, Surakarta, Indonesia

Wildan, Harun, Mohd \& Safrida, Yenni. 2015. Fakta Sejarah dalam Novel Perempuan Keumala Karya Endang Moerdopo. Cendekia, 9(1): 25 36.

\title{
FAKTA SEJARAH DALAM NOVEL PEREMPUAN KEUMALA KARYA ENDANG MOERDOPO
}

\author{
Wildan *) \\ Mohd. Harun *) \\ Yenni Safrida **) \\ *) Dosen FKIP Universita Syiah Kuala, Banda Aceh \\ **) Mahasiswa MPBSI PPs Unsyiah Banda Aceh \\ Email: mohar1966@yahoo.com
}

\begin{abstract}
This study aims at analyzing historical facts encountered in the novel Keumala Woman (Perempuan Keumala) written by Endang Moerdopo. The analyses comprises of historical facts about: (1) Keumalahayati, (2) historical events, and (3) places having historical story. Data of this study are sequences of events in the novel pertaining to historical realities. New historicism analysis is used to describe the data. The study reveals some findings. First, Keumalahayati is a royal woman who finished her education in Military Academy Makhad Baitul Makdis. Several names that supports historical fact is her husband Sultan Alaiddin Riayat Syah, Cut Limpah, Alfonso, Sultan Muda, Cornelis de Houtman and Frederick de Houtman. Second, historical events incurred in the novel included the development of Makhad Baitul Makdis, the war to Portoguuese in Teluk Haru, rebellion of Sultan Muda, and the arrival of the Dutch for the first time in Aceh. Third, name of places supporting historical facts consisted of Makhad Baitul Makdis, kingdom palace, Krueng Raya Harbor, Pulau Weh, Benteng Inong Balee, Teluk Haru, and Tamiang. This novel is in fact a historical novel particularly that describes the heroism of Keumalahayati.
\end{abstract}

Keywords: novel, historical events, Ducth.

Penelitian ini berhubungan dengan kajian fakta sejarah yang terdapat dalam novel bernuansa sejarah, khususnya sejarah Aceh. Novel tersebut berjudul Perempuan Keumala karya Endang Moerdopo. Fokus penelitian meliputi tiga aspek, yaitu sejarah tentang tokoh Keumalahayati, peristiwa sejarah yang terjadi, dan penggunaan nama tempat bersejarah. Ketiga aspek tersebut dikaji untuk menemukan fakta sejarah dalam novel tersebut.

Penelitian ini dilandasi pemikiran berikut. Endang Moerdopo adalah salah seorang perempuan Indonesia yang memiliki ketertarikan dan kecintaan mendalam terhadap tokoh Pahlawan Perempuan Aceh Laksamana Keumalahayati. Menteri Negara Pemberdayaan Perempuan, Prof. Dr. Meutia Hatta Swasono (Moerdopo:2008) dalam sambutan pada novel ini menyebutkan bahwa Endang Moerdopo berhasil meramu fakta sejarah yang yang selama ini terpendam menjadi suatu karya sastra yang bertema sejarah, yaitu sejarah Pahlawan Perempuan Aceh Laksamana Keumalahayati. Lebih lanjut, Meutia memaparkan bahwa novel Perempuan Keumala ini adalah salah satu bacaan berbentuk novel yang berisi cerita sejarah yang akurat berdasarkan arsip sejarah yang autentik. Berdasarkan pemaparan tersebut, perlu 
CENDEKIA, Vol. 9, No. 1, April 2015

p ISSN: 1978 2098; e ISSN: 2407 8557; Web: cendekia.pusatbahasa.or.id

Pusat Kajian Bahasa dan Budaya, Surakarta, Indonesia

Wildan, Harun, Mohd \& Safrida, Yenni. 2015. Fakta Sejarah dalam Novel Perempuan Keumala Karya Endang Moerdopo. Cendekia, 9(1): 25 36.

dikaji fakta sejarah yang menjadi salah satu objek utama lahirnya novel ini. Artinya, perlu dianalisis, apakah benar bahwa fakta sejarah terdapat dalam novel ini atau sebaliknya.

Penelitian ini didasari oleh pendekatan new historiscm. Kritik new historiscm sangat perlu dilakukan terhadap novel Perempuan Keumala untuk melihat bagaimana fakta sejarah diramu dalam bahasa sastra. Implikasi dari penelitian ini adalah sumbangan baru terhadap perkembangan kritik sastra Indonesia dan perkembangan sejarah sastra Indonesia modern khususnya, serta memaknai bagaimana realitas sejarah dibangun dalam teks-teks sastra.

Selanjutnya, penelitian ini juga dilakukan berdasarkan pemikiran bahwa Laksamana Keumalahayati layak dijadikan sebagai salah satu tokoh penggerak perempuan yang dapat membuktikan bahwa Islam tidak membatasi perempuan untuk aktif bahkan untuk menjadi seorang pemimpin pasukan perang salah satu kerajaan yang terkenal di dunia. Laksamana Keumalahayati telah banyak mengukir prestasi. "Ia adalah seorang laksamana perempuan pertama di dunia. Perempuan yang untuknya tidak ada lagu pujian. Pahlawan yang tidak pernah diukir sejarahnya. Seorang pemimpin yang disegani lawan dan kawan" (Saifullah, 2012:13). Dengan demikian, rakyat Indonesia pada umumnya, dan rakyat Aceh khususnya, dapat mengenal lebih mendalam mengenai sosok perempuan perkasa ini, yang terlahir jauh sebelum R.A. Kartini yang dijadikan sebagai tokoh pahlawan yang memperjuangkan hak-hak perempuan.

Alasan berikutnya, novel ini dapat dijadikan sebagai salah satu materi pada pembelajaran sastra di sekolah. Selain itu, melalui novel ini guru akan mudah mengenalkan sejarah kepada siswa melalui karya sastra. Siswa akan lebih tertarik untuk mengenal sejarah, khususnya sejarah pahlawan Laksamana Keumalahayati. Bagaimanapun, novel adalah salah satu bentuk karya sastra yang menjadi alat komunikasi yang khas dalam kehidupan manusia. Selain itu, sampai saat ini analisis mengenai fakta sejarah dalam novel Perempuan Keumala karya Endang Moerdopo belum pernah diteliti. Oleh sebab itu, penelitian ini menjadi penelitian pertama mengenai masalah ini dan dapat menjadi acuan untuk peneliti selanjutnya.

Berdasarkan uraian di atas, masalah penelitian ini meliputi (1) fakta sejarah tentang tokoh Keumalahayati, (2) fakta sejarah tentang peristiwa, (3) fakta sejarah tentang penggunaan nama tempat yang terdapat dalam novel Perempuan Keumala karya Endang Moerdopo.

Perkembangan novel sangat pesat. Salah satu di antaranya adalah novel yang bernuansa sejarah. Hal ini ditandai banyaknya novel sejarah yang dihasilkan, seperti Suropati dan Robert Anak Suropati karya Abdul Muis, Kembang Jepun karya Remy Sylado, Kapal Terbang Sembilan karya M. Yanis, Hulu Balang Raja karya Nur Sutan Iskandar, Pelangi di Atas Glogahwangi karya S. Tijab, Senja di Langit Majapahit karya Herman Aksan, dan lain sebagainya (Sungkowati, 2009:2).

Maraknya novel-novel bertemakan sejarah tersebut mengundang diskusi yang menarik di kalangan pengamat atau pelaku sastra dan sejarawan berkaitan dengan hubungan antara sastra dan sejarah. Hal ini dipaparkan oleh Kuntowijoyo yang dikutip oleh Sungkowati dalam jurnal Lingua (2009:2). Kuntowijoyo mengemukakan bahwa objek karya sastra adalah realitas (apa pun yang dimaksud realitas oleh pengarangnya). Jika realitas yang dijadikan sebagai objeknya adalah peristiwa sejarah, karya sastra dapat menerjemahkan peristiwa itu dalam imajinasi dengan maksud untuk memahami peristiwa sejarah menurut kadar kemampuan 
CENDEKIA, Vol. 9, No. 1, April 2015

p ISSN: 1978 2098; e ISSN: 2407 8557; Web: cendekia.pusatbahasa.or.id

Pusat Kajian Bahasa dan Budaya, Surakarta, Indonesia

Wildan, Harun, Mohd \& Safrida, Yenni. 2015. Fakta Sejarah dalam Novel Perempuan Keumala Karya Endang Moerdopo. Cendekia, 9(1): 25 36.

pengarangnya. Selain itu, sejarah juga dapat menjadi sarana bagi penulis karya sastra untuk menyampaikan perasaan, pikiran, dan tanggapan mengenai suatu peristiwa sejarah. Sejarah juga dapat ditulis kembali sebagai suatu cerita yang mengisahkan suatu peristiwa sejarah yang pernah terjadi di masa lampau sesuai dengan pengetahuan dan kronologis sejarah.

Ada satu ruang lingkup dalam kesusastraan yang seringkali menimbulkan pertentangan, yaitu ketika sastra menyinggung tentang fakta. Sastra seringkali dibatasi sebagai salah satu wilayah seni yang menggarap fiksi, sedangkan fakta diartikan masuk wilayah kajian sejarah atau ilmu-ilmu sosial lainnya. Misalnya, ketika membaca novel The Lord of the Rings, seorang pembaca dapat menerima logika adanya berbagai macam jenis manusia, termasuk hobbit, kurcaci, penyihir, manusia peri, dan aneka jenis manusia lain yang seram bentuknya. Lalu, bagaimana ketika seseorang membaca novel-novel yang kontroversial seperti Salman Rusdie yang mendeskreditkan Nabi Muhammad seperti terdapat dalam AyatAyat Setan (The Satanic Verses?) Sama halnya dengan pemisalan tersebut berkaitan dengan kajian-kajian sastra ketika disandingkan dengan ilmu yang lain, dalam konteks ini sejarah (Nurhadi, 2005:1).

Karya sastra pada dasarnya adalah seni bahasa, karena dalam pembangunan dunianya, karya sastra menggunakan medium bahasa. Salah satu jejak yang secara sengaja dan sadar dipelihara dan diteruskan untuk menjadi bahan informasi kepada generasi berikutnya adalah seni. Seni bermacam-macam wujudnya, di antaranya adalah seni rupa, seni musik, dan seni sastra. Seni sastra termasuk dalam jejak tertulis, jejak material yang dapat dipahami informasinya melalui media bahasa (Sugihastuti, 2002:159-160).

Seni sastra memang tidak dapat dipisahkan dengan masyarakat. Hakikat masyarakat dan kebudayaan pada umumnya adalah kenyataan, sedangkan hakikat karya sastra adalah rekaan yang lebih dikenal dengan sebutan imajinasi. Berbeda dengan kenyataan dalam ilmu kealaman, kenyataan dalam ilmu sosial adalah kenyataan yang telah ditafsirkan, kenyataan sebagai fakta sosial. Berbeda dengan imajinasi dalam kehidupan sehari-hari, yang dianggap sebagai semata-mata khayalan, imajinasi dalam karya sastra adalah imajinasi yang didasarkan atas kenyataan, imajinasi yang juga diimajinasikan oleh orang lain. Sebagai karya seni, karya sastra tidak secara keseluruhan merupakan imajinasi. Hal itu dijelaskan oleh Ratna (2007:360) sebagai berikut. (1) Meskipun hakikat karya sastra adalah rekaan, tetapi sudah jelas bahwa karya sastra didekontruksi berdasarkan kenyataan. (2) Dalam setiap karya sastra, terkandung unsur-unsur tertentu yang sifatnya objektif. Umumnya fakta-fakta tersebut berupa nama orang, nama-nama tempat (toponim), pristiwa-peristiwa bersejarah, monumen, dan sebagainya. (3) Karya sastra yang secara keseluruhan merupakan imajinasi justru tidak dapat dianalisis, tidak dapat dipahami secara benar karena tidak memiliki relevansi sosial.

Wilayah pengkajian sastra sebenarnya suatu wilayah yang sangat luas akan ruang lingkup kajiannya. Kajian sastra tidak hanya terbatas pada kajian dalam lingkup sastra itu sendiri, misalnya tidak hanya terbatas pada kajian mengenai unsur pembangunnya seperti kajian mengenai tema, tokoh, latar, gaya bahasa, dan lain sebagainya. Namun, ranah kajian sastra juga dapat merambah pada ilmu di luar karya sastra itu sendiri. Contohnya, kajian sastra dapat disandingkan dengan ilmu-ilmu sosial seperti ilmu politik, hukum, antropologi, sosiologi, ekonomi, sejarah, dan lain sebagainya. Dalam penelitian ini, kajian sastra akan disandingkan dengan ilmu sejarah. 
CENDEKIA, Vol. 9, No. 1, April 2015

p ISSN: 1978 2098; e ISSN: 2407 8557; Web: cendekia.pusatbahasa.or.id

Pusat Kajian Bahasa dan Budaya, Surakarta, Indonesia

Wildan, Harun, Mohd \& Safrida, Yenni. 2015. Fakta Sejarah dalam Novel Perempuan Keumala Karya Endang Moerdopo. Cendekia, 9(1): 25 36.

Sejarah itu sendiri sebenarnya berarti sebagai rekonstruksi masa lalu. Rekonstruksi sejarah ialah apa saja yang telah dipikirkan, dikatakan, dikerjakan, dirasakan, dan dialami oleh orang. Itulah yang disebut sejarah (Kuntowijoyo, 2005:18).

Sastra dan sejarah memiliki hubungan timbal balik.Suatu karya sastra dapat menjadikan peristiwa sejarah sebagai objeknya dan sebaliknya, karya sastra juga dapat menjadi sumber penulisan sejarah. Seseorang mungkin saja akan keberatan jika sebuah karya sastra harus dipahami dengan pertanyaan-pertanyaan nonsastra. Namun, keberatan itu dapat diseliminasi jika diawali dengan suatu asumsi dasar bahwa karya sastra adalah hasil dari suatu konteks tertentu, sebagaimana pendapat Rokhman, dkk., (2003:143) bahwa karya sastra tidak dapat dilepaskan dari kolektivitas dan konteks historis yang melahirkannya.

Keterkaitan antara sastra dan sejarah juga dikemukakan oleh Teeuw. Menurut Teeuw, secara etimologi sastra dan sejarah, sebagai story dan history berasal dari kata yang sama, yaitu historia (Yunani). Story, yaitu cerita itu sendiri, jelas merupakan tulang punggung bagi sebuah karya, khususnya jenis karya sastra yang dikategorikan sebagai prosa (Sugihastuti, 2002:340).

Keterkaitan sastra dan sejarah juga diungkapkan oleh pakar sejarah Ardan (Kompas, 2007:14), bahwa sastra adalah pekerjaan imajinasi, kebenaran di tangan pengarang dengan perkataan lain bersifat subjektif. Sastra dapat berakhir dengan pertanyaan, sedangkan sejarah harus memberi informasi selengkap-lengkapnya. Asvi lebih lanjut mengungkapkan, sejarah dan sastra berkaitan dengan narasi. Sejarah, seperti halnya sastra, disampaikan oleh sejarawan melalui narasi. Narasi sejarah itu sendiri memakai plot. Selain itu, Asvi mengatakan sejarah juga dapat tidak akurat, yang jelas keduanya membutuhkan imajinasi dari penulisnya.

Selain keterkaitan dengan narasi, sastra dan sejarah juga berhubungan dari segi fakta. Sejarah tidak mungkin terlepas dari fakta yang disebut fakta sejarah. Sastra sendiri juga lahir dari sebuah fakta.

Fakta merupakan sesuatu hal yang benar-benar terjadi. Fakta dalam konteks ini dimaksudkan sebagai fakta yang terjadi pada perkembangan manusia itu sendiri karena faktafakta yang berkembang dalam kehidupan manusia ini sendirilah yang memengaruhi kehidupan manusia di masa datang. Fakta-fakta kemanusiaan mempunyai peranan dalam sejarah. Hal itu dapat berupa fakta individual dan fakta sosial atau historis. Revolusi sosial, politik, ekonomi, dan karya-karya kultural yang besar merupakan fakta sosial yang hanya mungkin diciptakan oleh subjek sehingga akan bermanfaat untuk karya sastra dan akan berdampak pada manusia pembaca khususnya.

\section{METODE}

Penelitian ini menggunakan pendekatan new historicism $(\mathrm{NH})$ yang mengaitkan antara teks sastra dan nonsastra (Budianta, 2006:1-3). Pendekatan NH digunakan untuk menganalisis fakta-fakta sejarah dalam novel Perempuan Keumala disesuaikan dengan teks sejarah di luar karya sastra. Sumber data utama penelitian ini adalah novel Perempuan Keumala karya Endang Moerdopo, diterbitkan oleh Grasindo Jakarta, tahun 2008. Data dikumpulkan melalui studi kepustaskaan dengan jalan membaca novel secara cermat dan mencatat secara rinci halhal yang berkaitan dengan sejarah Keumalahayati, peristiswa sejarah yang menyertainya, dan tempat bersejarah. Data yang sudah dikumpulkan kemudian dianalisis. Teknik analisis data 
CENDEKIA, Vol. 9, No. 1, April 2015

p ISSN: 1978 2098; e ISSN: 2407 8557; Web: cendekia.pusatbahasa.or.id

Pusat Kajian Bahasa dan Budaya, Surakarta, Indonesia

Wildan, Harun, Mohd \& Safrida, Yenni. 2015. Fakta Sejarah dalam Novel Perempuan Keumala Karya Endang Moerdopo. Cendekia, 9(1): 25 36.

menggunakan metode analisis deskriptif kualitatif. Metode deskriptif kualilatif merupakan metode penelitian yang menggambarkan objek penelitian dengan cara mendeskripsikan faktafakta. Selanjutnya, uraian tersebut disusul dengan analisis (Ratna, 2006:53). Analisis data dilakukan dengan langkah-langkah berikut (1) mengklasifikasikan data dengan cara memasukkannya dalam tabel instrumen yang telah disusun; (2) selanjutnya, menganalisis data sesuai dengan ruang lingkup penelitian. Analisis dilanjutkan setelah klasifikasi dari tabel instrumen dengan menggunakan pendekatan new historicism dengan cara mengaitkannya dengan fakta sejarah di luar karya sastra. Selanjutnya, menarik kesimpulan.

\section{HASIL DAN BAHASAN}

\section{Fakta Sejarah tentang Keumalahayati a. Silsilah Keumalahayati}

Keumalahayati digambar dalam $P K$ berasal dari keturunan bangsawan atau berdarah biru. Ia juga digambarkan sebagai keturunan Raja-raja Aceh dahulu sebelum Sultan Alaiddin Riayat Syah Al-Mukammil memerintah (1589-1604). Keumalahayati merupakan anak dari Laksamana Mahmud Syah yang berasal dari Aceh bagian Utara, Jeumpa. Dalam novel, Moerdopo melukiskan Laksamana Keumalahayati dari pihak ayahnya adalah keturunan dari Sultan Ibrahim Ali Mughayat Syah, pendiri Kerajaan Darud Donya Darussalam.

Pendeskripsian silsilah Keumalahayati dalam novel memiliki cerita serupa seperti fakta sejarah. Fakta sejarah menuliskan bahwa Keumalahayati memanglah seorang putri dari Laksamana Aceh yang terkenal, yang berjasa untuk nanggroe Aceh pada saat itu. Menurut fakta sejarah, ayah Keumalahayati memang bernama Laksamana Mahmud Syah. Kakek dari garis keturunan ayahnya juga seorang laksamana. Nama kakeknya adalah Muhammad Said Syah, yaitu putra dari Sultan Salahuddin Syah yang memerintah sekitar tahun 1530-1539 M. Sultan Salahuddin Syah sendiri merupakan anak dari pendiri Kerajaan Aceh Darussalam, yaitu Sultan Ibrahim Ali Mughayat Syah yang memerintah pada tahun 1513-1530 M (Salam,1995:25).

\section{b. Pendidikan Keumalahayati}

Berdasarkan cerita dalam PK, dari kecil Malahayati dibesarkan dalam lingkungan agama Islam. Keumala menempuh pendidikan nonformalnya, seperti mengaji di bale (surau) kampungnya untuk mempelajari hukum-hukum Islam sebagai agama yang sangat diyakininya. Selain itu, Keumala juga menempuh pendidikan formalnya di Kuta Raja di Akademi Militer Makhad Baitul Maqdis dengan memilih jurusan kemiliteran laut. Ia menyukai laut dari kecil. Hal ini mungkin karena ia merupakan keturunan dari Laksamana Aceh. Dalam novel dikisahkan ayah dan kakeknya merupakan seorang laksamana yang sangat berjasa untuk Aceh.

Fakta sejarah mengenai pendidikan Keumalahayati juga dipaparkan oleh Salam (1995:26) bahwa Keumalahayati menamatkan pendidikannya di Akademi Militer Makhad Baitul Makdis. Kampus ini dibangun dari hasil kerja sama Aceh dengan Turki Usmani. Aceh di masa pemerintahan Sultan Alauddin Riayat Syah Al-Qahar yang memerintah pada tahun 
CENDEKIA, Vol. 9, No. 1, April 2015

p ISSN: 1978 2098; e ISSN: 2407 8557; Web: cendekia.pusatbahasa.or.id

Pusat Kajian Bahasa dan Budaya, Surakarta, Indonesia

Wildan, Harun, Mohd \& Safrida, Yenni. 2015. Fakta Sejarah dalam Novel Perempuan Keumala Karya Endang Moerdopo. Cendekia, 9(1): 25 36.

1537-1571 mengirim seorang utusan ke Turki dipimpin oleh Husein Effendi. Sekolah militer ini terdapat dua jurusan, yaitu jurusan darat dan laut.

\section{c. Tokoh-tokoh Bersejarah Masa Keumalahayati}

Selain Keumalahayati, ada beberapa tokoh sejarah lain yang dihadirkan dalam novel $P K$. Tokoh-tokoh tersebut di antaranya adalah suami Keumalahayati, Sultan Alaiddin Riayat Syah Al Mukammil, Pocut Limpah, Alfonso, Sultan Muda, Cornelis de Houtman, dan Frederick de Houtman. Tokoh-tokoh tersebut tercatat dalam fakta sejarah. Suami Keumala, misalnya, merupakan seorang laksamana yang syahid dalam pertempuran di Teluk Haru. Perang melawan Portugis tersebut dipimpin langsung oleh Sultan Alaiddin Riayat Syah AlMukammil. Hal ini juga merupakan bukti bahwa Sultan Alaiddin juga tokoh sejarah yang diceritakan dalam novel PK.

Makhad Baitul Makdis telah menjadi saksi kisah cinta Keumala dan suaminya. Hal ini juga dikisahkan dalam novel. Sejalan dengan fakta sejarah, bahwa setelah pemuda ini (suami Keumala) menyelesaikan pendidikannya di Makhad Baitul Makdis, beberapa tahun kemudian Keumalahayati juga menyelesaikan studinya. Pertemuan mereka di pendidikan yang sama telah mengantarkan mereka menuju mahligai pernikahan (Wadji, dkk. 2008:354).

Tokoh bersejarah ketiga yang juga dihadirkan dalam novel ini adalah Cut Limpah. Fakta sejarah menuliskan bahwa ketika Keumalahayati diangkat menjadi kepala pasukan pengamanan istana dan sekaligus menjadi penasihat kerajaan sementara, Cut Limpah pun diamanahkan menjadi Ketua Dinas Rahasia (secret servicel geheimraad) Kerajaan Darud Donya Aceh Darussalam. Kebijakan tersebut dilakukan karena rasa percaya Sultan AlMukammil kepadanya (Azwar, 2011:138).

Tokoh lain adalah Alfonso, orang Portugis yang dipercayakan Sultan menjadi penerjemah kerajaan juga dihadirkan dalam novel ini. Fakta sejarah mengenai Don Alfonso Vicente juga dipaparkan oleh Husen (2008:46) bahwa ketika Aceh sedang berdamai dengan Portugis, di istaka Aceh juga ada seorang Portugis yang menjadi juru bahasa dan penasehat dagang sultan yang bernama Alfonso Vicente.

Tokoh sejarah berikutnya yang diceritakan dalam PK adalah Sultan Muda yang merupakan anak Sultan Alaiddin. Terakhir, Cornelis de Houtman dan Frederick de Houtman, dua bersaudara, yang merupakan orang Belanda pertama yang datang ke Aceh dengan membawa kapal masing-masing.

\section{d. Jabatan dan Pengaruh dalam Kerajaan}

Dalam novel Perempuan Keumala dikisahkan bahwa Keumalahayati adalah seorang perempuan yang berpangkat laksamana (admiral). Berikut ini kutipannya.

Menjadi mimpinya berlarut-larut setiap hari untuk dapat tumbuh besar di sini dan menjadi ceracaunya setiap masa untuk bisa menimba ilmu di tempat ini. Jiwa baharinya sudah tumbuh begitu luas dalam darahnya, roh keberaniaanya hidup dengan suburnya dalam napas keturunan tuan ini, duhai Tuanku Ahli..." (Moerdopo, 2008: 31) 
CENDEKIA, Vol. 9, No. 1, April 2015

p ISSN: 1978 2098; e ISSN: 2407 8557; Web: cendekia.pusatbahasa.or.id

Pusat Kajian Bahasa dan Budaya, Surakarta, Indonesia

Wildan, Harun, Mohd \& Safrida, Yenni. 2015. Fakta Sejarah dalam Novel Perempuan Keumala Karya Endang Moerdopo. Cendekia, 9(1): 25 36.

Jabatan-jabatan Keumalahayati yang digambarkan dalam novel juga sesuai dengan fakta sejarah. Sejarah mencatat bahwa Keumala memang pernah menjadi Komandan Protokol Kerajaan Darud Donya. Dalam konteks ini, Hasjmy (1993:240) memaparkan bahwa Keumala memang pernah menjabat sebagai Komandan Protokol Kerajaan Darud Donya Aceh Darussalam. Ketika suaminya mati di Teluk Haru untuk mengusir Portugis, Keumalahayati masih menjabat sebagai Komandan Protokol Kerajaan Aceh Darussalam pada saat itu.

Jabatan ketiga Keumalahayati adalah Panglima Pasukan Inong Balee. Sepeninggal suaminya, Keumala meminta izin kepada Sultan Al-Mukammil untuk membentuk pasukan yang terdiri dari wanita-wanita janda yang ditinggal mati suaminya di Perang Teluk Haru sama seperti dirinya.

\section{Peristiwa Bersejarah}

\section{a. Pendirian Makhad Baitul Maqdis}

Menurut pendapat Salam (1995:16), pembangunan akademi militer Makhad Baitul Maqdis lahir dari hasil kerja sama Aceh dengan Turki. Sultan Alauddin Riayat Syah AlQahhar pernah mengirim utusan ke Turki yang dipimpin oleh Husein Effendi. Pada saat itu, Turki sedang berada pada puncak kejayaannya. Wilayah kekuasaan Turki sangatlah besar, dari Maghrib sampai Kaukakus dari gerbang Wina di Eropa. Kisah ini juga diuraikan dalam PK. Berikut kutipan pembuktiannya.

Di tempat belajar ini pulalah Kerajaan darud Donya Aceh Darussalam mencetak perwira-perwira pemberani yang siap membela naggroe yang sudah sejak lama terkenal keberaniannya. Kekuatan militer yang sangat tangguh adalah warisan dari pemerintah sebelumnya, Sultan Alauddin Ria'yat Syah Al-Qahar, yang kemudian menjalin persahabatan dengan Turki, Arab, dan India, untuk semakin memperkuat pertahanan (Moerdopo, 2008:19).

\section{b. Perang di Teluk Haru}

Ada tiga peristiwa penting yang terjadi berhubungan dengan peperangan di Teluk Haru ini. Pertama adalah peristiwa penyambutan kemenangan yang dijalankan oleh seluruh rakyat Aceh. Peristiwa penyambutan ini dilakukan dengan menampilkan acara-acara kesenian khas Aceh.

Peristiwa berikutnya adalah peristiwa syahidnya suami Keumalahayati. Fakta sejarah mencatat suami Keumalahayati adalah seorang laksamana. Raja Al-Mukammil memercainya dengan memberi jabatan sebagai Panglima Selat Malaka karena ketangkasannya dalam 'melaut'. Hal ini juga diungkapkan oleh Azwar (2011:141), bahwa salah seorang laksamana yang diikutsertakan dalam peperangan di Teluk Haru oleh Sultan Al-Mukammil gugur ketika sedang bertempur melawan Portugis adalah suami Keumalahayati.

Selain peristiwa yang berhubungan dengan perang di Teluk Haru, dikisahkan juga peristiwa pembentukan Pasukan Inong Balee. Sepeninggal suaminya, Keumalahayati meminta agar dirinya dibebaskan menjadi Komandan Protokol Kerajaan Aceh. Selain itu, Keumalahayati juga meminta izin agar diperbolehkan membentuk pasukan wanita yang terdiri dari para wanita janda yang suaminya gugur di Teluk Haru. 
CENDEKIA, Vol. 9, No. 1, April 2015

p ISSN: 1978 2098; e ISSN: 2407 8557; Web: cendekia.pusatbahasa.or.id

Pusat Kajian Bahasa dan Budaya, Surakarta, Indonesia

Wildan, Harun, Mohd \& Safrida, Yenni. 2015. Fakta Sejarah dalam Novel Perempuan Keumala Karya Endang Moerdopo. Cendekia, 9(1): 25 36.

Sama halnya seperti yang tertulis dalam sejarah, Sultan akhirnya menerima permintaan Keumala. Sultan Al-Mukammil melantik Keumala sebagai Panglima Pasukan Inong Balee (Wadji, dkk. 2008:354).

\section{c. Pengkhiatanan Sultan Muda}

Raja Muda Ali Riayat Syah itulah nama lengkap Sultan Aceh Darussalam ke-5. Raja Muda Ali adalah anak dari Sultan Alaiddin Riayat Syah Al-Mukammil. Sultan Muda Ali merupakan raja yang berambisi tinggi. Bagaimana tidak, ia sengaja menggulingkan ayahnya sendiri agar kursi kerajaan segera menjadi miliknya (Djamil, 2009:166). Hal ini pula yang dilukiskan Moerdopo dalam novelnya. Pengkhianatan Sultan Muda juga merupakan salah satu peristiwa penting yang dikisahkan dalam novel ini.

\section{d. Belanda Datang ke Aceh}

Pada tanggal 21 Juni 1599 dua kapal Belanda datang ke Aceh. Mereka tepat berlabuh di pelabuhan Banda Aceh. Peristiwa ini dikembangkan ceritanya di dalam novel Perempuan Keumala. Belanda disambut baik di Aceh. Namun, kesempatan yang diberikan Aceh kepada Belanda tidak dipergunakan dengan baik. Beberapa saat setelah keberadaannya di Aceh, Belanda mulai menunjukkan sikap kolonialismenya. Hal ini juga merupakan peristiwa penting sebagai bentuk pengkhianatan Belanda terhadap Sultan Aceh. Sambutan yang baik dari pihak Kesultanan Aceh akhirnya berubah menjadi permusuhan. Belanda sering membuat onar dan keributan di pasar-pasar di Aceh. Bahkan kedua bersaudara, Cornelis dan Frederick, mengkhianati Sultan Al-Mukammil dengan membuat manipulasi dagang, mengacau, dan menghasut, sehingga timbul ketegangan di kalangan para pedagang yang datang dari luar negeri (Wadji, dkk. 2008:355).

Akibat pengkhiatan Belanda terhadap Aceh, akhirnya terjadilah perlawanan Aceh terhadap Belanda sehingga menewaskan pemimpin Belanda pada saat itu. Dari ketegangan tersebut, terjadilah ketegangan yang semakin parah antara Aceh dan Belanda. Belanda memanipulasi perdagangan. Sultan Al-Mukammil pun memerintahkan Keumalahayati sebagai Panglima Pasukan Inong Balee untuk menyerang kapal-kapal Belanda tersebut. Pertempuran sengit pun terjadi. Akhirnya, Cornelis tewas dalam pertempuran dibunuh oleh Keumalahayati. Sementara itu, Frederick mendekam di Penjara Aceh selama dua tahun dan berhasil menulis kamus Melayu-Belanda pertama di Nusantara.

\section{Tempat-Tempat Bersejarah a. Makhad Baitul Makdis}

Makhad Baitul Makdis dalam tulisan-tulisan sejarah dijelaskan memang pernah ada. Letak kampus yang telah berhasil mendidik taruna-taruna Aceh ini berada di salah satu sudut kota Banda Aceh. Daerah tersebut disebut daerah Bitay (baital). Tempat tersebut memang ada kaitannya dengan orang-orang Turki. Banyaknya buku-buku mengenai agama Islam dan teknik yang dibawa oleh rombongan Turki telah hancur ketika perpustakaan terbakar dalam Perang Dunia II (Salam, 1995:17). Penggunaan nama tempat Makhad Baitul Maqdis juga dilukiskan dalam novel. 
CENDEKIA, Vol. 9, No. 1, April 2015

p ISSN: 1978 2098; e ISSN: 2407 8557; Web: cendekia.pusatbahasa.or.id

Pusat Kajian Bahasa dan Budaya, Surakarta, Indonesia

Wildan, Harun, Mohd \& Safrida, Yenni. 2015. Fakta Sejarah dalam Novel Perempuan Keumala Karya Endang Moerdopo. Cendekia, 9(1): 25 36.

\section{b. Istana Darud Donya}

Menurut fakta sejarah, istana (dalam) terletak tidak jauh dari pekan. Istana ini berada di tepi sungai yang oleh Davis, seorang saksi sejarah di masa pemerintahan Sultan Alaiddin Riayat Syah Al-Mukammil, disebut sangatlah cantik. Selain itu, Davis melanjutkan, istana itu besar dan berkolong. Istana (dalam) berberanda tiga lapis, yang harus dilalui dulu sebelum masuk ke dalam. Dari tempatnya, sultan dapat melihat segala-galanya, tanpa orang bisa melihat dia. Ruangan dihiasi dengan tabir bahan emas. Di sana-sini, kain sutera. Pendeskripsian mengenai pelayanan terhadap sultan Alaiddin juga diceritakan oleh Davis. Davis menceritakan sejumlah 40 dayang-dayang istana sebagian mengipasi baginda. Sultan menyandang empat keris, dua di muka, dua di belakang ditatah permata mutu menikam". Begitulah deskripsi istana (dalam) yang digambarkan Davis pada masa A-Mukammil memegang kuasa (Said, 2000:191).

\section{c. Pelabuhan Krueng Raya}

Bukti sejarah yang menyatakan bahwa memang pernah ada Teluk Krueng Raya juga disampaikan oleh Salam (1995:35). Salam menyatakan Keumalahayati bahkan syahid di Teluk Kreung Raya ketika sedang melawan Portugis.

\section{d. Pulau Weh}

Davis, seorang saksi sejarah yang berkebangsaan Inggris (dalam Said, 2000:192) menyatakaan kesannya mengenai Kerajaan Aceh adalah masalah hukuman yang berlaku. Hukuman terhadap orang-orang yang bersalah ada bermacam-macam. Misalnya seperti hukum potong, hukum buang ke Pulau Weh, dan juga hukuman mati. Selain itu, juga ada hukuman penjara. Pulau Weh adalah salah satu nama tempat yang digunakan dalam novel ini.

\section{e. $\quad$ Benteng Inong Balee}

Penggunaan nama tempat Benteng Inong Balee sebagai tempat latihan pasukan wanitwanita janda yang dilatih Keumala di dalam novel Moerdopo merupakan suatu fakta sejarah. Sesuai dengan fakta sejarah, Keumala juga meminta izin kepada Sultan Al-Mukammil untuk menjadikan benteng pertahanan di Krueng Raya sebagai Benteng Pasukan Inong Balee yang dipimpinnya. Dalam kaitan ini, Sufi (2008:32) menyatakan bahwa untuk kepentingan latihan Pasukan Inong Balee akhirnya didirikanlah sebuah benteng yang dalam istilah Aceh disebut Kuta Inong Balee (Benteng Wanita Janda). Hingga saat ini, benteng tersebut masih ada dan dapat ditemukan di Teluk Krueng Raya, dekat dengan Pelabuhan Malahayati.

\section{f. Sekitar Teluk Haru}

Untuk menuju ke Teluk Haru, dalam novel, digambarkan Sultan Alaiddin Riayat Syah Al-Mukammil dan pasukannya singgah di Kerajaan Tamiang. Apabila dilihat fakta sejarah dahulu, memang ada Kerajaan Tamiang. Kerajaan Tamiang adalah salah satu Kerajaan Islam. Kerajaan ini adalah kerajaan yang diperintahkan secara turun-temurun, yang pertama kali diperintah oleh pendatang yang berasal dari Alas yang menganut Islam (Husen, 2008:41).

Teluk Haru atau sebagian orang menyebut Aru terletak di daerah Provinsi Sumatera Utara (sekarang). Teluk Haru ini dahulu juga adalah salah satu kekuasaan Aceh. Namun, 
CENDEKIA, Vol. 9, No. 1, April 2015

p ISSN: 1978 2098; e ISSN: 2407 8557; Web: cendekia.pusatbahasa.or.id

Pusat Kajian Bahasa dan Budaya, Surakarta, Indonesia

Wildan, Harun, Mohd \& Safrida, Yenni. 2015. Fakta Sejarah dalam Novel Perempuan Keumala Karya Endang Moerdopo. Cendekia, 9(1): 25 36.

seiring dengan datangnya orang Portugis, Teluk Haru dikuasai mereka. Teluk Haru ini tepatnya terletak di Pangkalan Berandan sekarang (Said, 2000:187).

\section{PENUTUP}

Berdasarkan hasil penelitian dan pembahasan disimpulkan hal-hal berikut. Pertama, fakta sejarah yang berhubungan dengan Keumalahayatai ditemukan bahwa Keumalayati berasal dari keturunan bangsawan dan menamatkan pendidikannya di Akademi Militer Makhad Baitul Makdis. Penggunaan tokoh-tokoh yang sesuai dengan fakta sejarah dalam novel Perempuan Keumala ini adalah suami Keumalahayati, Sultan Alaiddin Riayat Syah, Cut Limpah, Alfonso, Sultan Muda, Cornelis de Houtman, dan Frederick de Houtman. Fakta menganai jabatan yang pernah dijalankan Keumalahayati adalah menjadi laksamana, komandan protokol kerajaan, dan Panglima Pasukan Inong Balee. Kedua, peristiwa-peristiwa bersejarah yang terdapat dalam novel ini adalah peristiwa pendirian Makhad Baitul Makdis, perang dengan Portugis di Teluk Haru, peristiwa pengkhianatan Sultan Muda, dan peristiwa datangnya Belanda pertama kali ke Aceh. Ketiga, penggunaan nama-nama tempat yang sesuai dengan fakta sejarah adalah Makhad Baitul Makdis, istna kerajaan, Pelabuhan Krueng Raya, Pulau Weh, Benteng Inong Balee, Teluk Haru, dan Tamiang. Ketiga, novel ini dapat disebut novel sejarah yang mengandung fakta sejarah sehingga dapat dijadikan salah satu alternatif pembelajaran sastra dan sejarah, khususnya sejarah Keumalahayati. Dengan demikian, novel ini tidak hanya ditulis berdasarkan imajinasi penulis semata namun juga berdasarkan fakta sejarah yang ada. Selain itu, penggunaan pendekatan kritik new historism ini sangat bermanfaat untuk melihat fakta yang terkandung dalam novel.

\section{DAFTAR PUSTAKA}

Ardan, Asvi Warman. 2006. “Antara Sastra dan Sejarah”. Dalam Kompas, 30 Setember.

Azwar, Pocut Muda Dalam. 2011. Perempuan Bercahaya dalam Lintas Sejarah Aceh. Jakarta: Yayasan Tun Sri Lanang.

Budianta, Melani. 2006. "Budaya, Sejarah, dan Pasar: New Historicism dalam Perkembangan Kritik Sastra”. Dalam Jurnal Susastra 3. Vol 2, No.3. 2006, Halaman 1-19.

Djamil, Muhammad Junus. 2009. Gerak Kebangkitan Aceh. Bandung: Bina Biladi Press.

Hasjmy, Ali. 1993. Wanita Aceh sebagai Negarawan dan Panglima Perang. Jakarta: Karya Unipress.

Husen, Usman. 2008. Aceh Serambi Mekkah. Banda Aceh: Pemda Provinsi Aceh.

Kuntowijoyo. 2005. Pengantar Ilmu sejarah.Yogyakarta: Bentang.

Moerdopo, Endang. 2008. Perempuan Keumala. "Novel”. Jakarta: Grasindo.

Nurhadi. 2005. "Batas Antara Fakta dan Fiksi dalam Tema Religiusitas". Dalam Jurnal Penelitian Agama STAIN Purwokerto. Nomor 35, Juli-Desember 2005, Halaman 1-11. Diunduh dari http://staff.uny.ac.id/sites/default/files/Batas Antara Fakta dan Fiksi dalam.Pdf.05 Juli 2014.

Ratna, Nyoman Kutha 2006.Teori Metode dan Teknik Penelitian Sastra.Yogyakarta: Pustaka Pelajar. 
CENDEKIA, Vol. 9, No. 1, April 2015

p ISSN: 1978 2098; e ISSN: 2407 8557; Web: cendekia.pusatbahasa.or.id Pusat Kajian Bahasa dan Budaya, Surakarta, Indonesia

Wildan, Harun, Mohd \& Safrida, Yenni. 2015. Fakta Sejarah dalam Novel Perempuan Keumala Karya Endang Moerdopo. Cendekia, 9(1): 25 36.

Ratna, Nyoman Kutha. 2007. Sastra dan Cultural Studies: Representasi Fiksi dan Fakta.

Yogyakarta: Pustaka Pelajar.

Rokhman, dkk.. 2003. Sastra Interdisipliner: Menyandingkan Sastra dan Disiplin Ilmu Sosial. Yogyakarta: Qalam.

Said, Mohammad. 2000. Aceh Sepanjang Abad Jilid I. Aceh: Pemda Aceh.

Saifullah. 2012. Laksamana Keumalahayati. Banda Aceh: Balai Pelestarian Sejarah dan

Nilai Tradisional.

Salam, Solichin. 1995. Malahayati: Srikandi dari Aceh. Jakarta: Ikrar Mandiriabadi.

Sufi, Rusdi. 2008. Aceh Tanah Rencong. Banda Aceh Pemerintah Provinsi Nanggroe Aceh Darussalam.

Sugihastuti. 2002. Teori dan Apresiasi Sastra. Yogyakarta: Pustaka Belajar.

Sungkowati, Yulitin. 2009. "Lintas Sejarah Indonesia Novel Suparto Brata". Dalam Jurnal Lingua, Vol. 4, No.1, Juni 2009, Halaman 1-10. Diunduh dari http://idci.dikti.go.id/pdf/Jurnal/Jurnal/Lingua/Vol 4, No. 1, Juni 2009/ Lintas Sejarah Indonesia dalam Novel.pdf.05 Juli 2014.

Wadji, Farid, dkk. 2008. Aceh Bumi Srikandi. Banda Aceh: Pemerintah Provinsi Nanggro Aceh Darussalam. 
CENDEKIA, Vol. 9, No. 1, April 2015

p ISSN: 1978 2098; e-ISSN: 2407 8557; Web: cendekia.pusatbahasa.or.id

Pusat Kajian Bahasa dan Budaya, Surakarta, Indonesia

Wildan, Harun, Mohd \& Safrida, Yenni. 2015. Fakta Sejarah dalam Novel Perempuan Keumala Karya Endang Moerdopo. Cendekia, 9(1): 25 36. 